\title{
A Study on Modification of Micro-Alloy Steel Surfaces with Different Hard Materials Via Electro-Spark Deposition Method
}

\author{
A. ÇakiR, M.S. Yilmaz, A. Ribalko, K. Korkmaz* \\ Gebze Institute of Technology, Department of Materials Science and Engineering, 41400 Gebze, Kocaeli, Turkey
}

\begin{abstract}
In this study, micro alloy steel (St 35) surfaces, which were coated with different hard alloy electrode materials via Electro Spark Deposition (ESD) method, have been characterized. The electrode materials were chosen among hard alloys such as; $\mathrm{TiCN}(\mathrm{Ni}), \mathrm{CrC}-\mathrm{NiCr}, \mathrm{WC}(\mathrm{Co})$ and $\mathrm{TiWC}(\mathrm{Co})$. During the ESD experiments, the following pulse parameters in a group were used: pulse current amplitude, pulse duration, electrical charge of 100-200 A, $100 \mu \mathrm{s}, 1000 \mathrm{mC}$ respectively. The surface roughness, thickness of coatings, cross sectional microstructure analysis, phase analysis, micro hardness and adhesion properties of the coated samples were characterized by profilometer, SEM (EDX), XRD, micro hardness tester and scratch adhesion tester respectively.
\end{abstract}

DOI: 10.12693 /APhysPolA.127.1410

PACS: 81.05.Bx, 82.45.Fk, 81.65.Lp.

\section{Introduction}

Coating processes or surface modification methods are the most widely used techniques to improve of surface properties for materials (for example steel). The electro spark deposition (ESD) process is a surface treatment method to produce hard and wear-resistant coating on various metallic materials, especially on micro-alloy steels [1-4]. In the ESD method, high current-low voltage electrical pulse of short duration is used to alloy an electrode material with a substrate material. Since this process allows the use of any electrical conductor material as the electrode, it can be possible to form ultra hard ceramic or cermet coatings on the metallic substrates. This process can produce metallurgical bonding between the coatings and substrates depending on the process parameters, resulting in a much better coating adhesion, compared to other low-energy coating processes $[5,6]$. Thus, the pair of the electrode and the substrate material, which were selected, is an important parameter for coating process [7].

The main objective of present study is to compare the effects of some hard electrode materials on the deposit layers, which are obtained using the ESD coating technique. With this aim, the ESD technique has been successfully applied to deposit some hard alloy materials on micro-alloy steel substrates in this study. And then, the mechanical and surface properties of coatings were investigated experimentally.

\section{Experimental procedure}

In the coating process experiments, a special ESD machine was employed. The ESD coating system was de-

*corresponding author; e-mail: korkmazk@gyte.edu.tr scribed in detail in previous studies $[8,9]$. Hard alloys electrode materials were deposited on the microalloy steel samples in air, using a series of rectangular shape pulses of certain duration of $100 \mu$ s and with amplitudes of current between 100-200 A. The frequencies of pulses were estimated to be about $50-100 \mathrm{~Hz}$, by considering the requirements of maintaining the constant charge $(1000 \mathrm{mC})$ during the process.

In the present study, $\mathrm{TiCN}(5 \%-\mathrm{Ni}), \mathrm{CrC}-\mathrm{NiCr}(20 \%-$ $\mathrm{Ni})$, WC $(8 \%-\mathrm{Co})$ and TiWC $(3 \%-\mathrm{Co})$ hard alloys, which were selected as the treating electrodes materials, have been produced by a conventional powder metallurgy and sintering technique [1]. The powder mixtures contain some amount of $\mathrm{Ni}$ or Co powders as a liquid-phase additive for sintering. The electrodes had a cross section of approximately $3 \times 5 \mathrm{~mm}^{2}$ and the steel (St 35) substrates were of cubic shape, with volume of $1 \mathrm{~cm}^{3}$.

After the coating processes, roughness measurements were performed with a profilometer device (SJ-400 Mitutoyo). The average roughness values ( $R a)$ of five measurements were reported for every coated surface of samples, for each processing condition. And also the thicknesses of the coatings were measured via eddy current method (Fischer Dualscope MP40) at 5 randomly selected locations for every coated surface (with total of 20 measurements for each sample).

Vickers microhardness (HV) measurements were taken on polished cross-sections of the coatings. These measurements were made with a microhardness tester (MHT10 Microhardness Tester, Anton Paar) at a load of $50 \mathrm{~g}$ and a loading time of $10 \mathrm{~s}$. Metallographic analysis was carried out using an optical microscope (Zeiss Avio, Imager) equipped with Video Test Structure software.

The adhesion strengths of the coatings were determined via a commercially available micro/macro scratch tester (Nanovea Series), equipped with optical microscope, tangential friction force sensor and penetration 
depth sensor. During the test, a linearly increasing load was applied to a static indenter at a loading rate of $60 \mathrm{~N} / \mathrm{min}$, while the sample was moved with a table at a speed of $1 \mathrm{~mm} / \mathrm{min}$. At the same time, the friction forces were recorded. A Rockwell $\mathrm{C}$ diamond indenter with a radius of $500 \mu \mathrm{m}$ was used in the test, and the applied scratch load was from $0 \mathrm{~N}$ to $175 \mathrm{~N}$ during the test.

Both, the surface morphology of the coated samples and the thickness of the deposited layer were investigated using a scanning electron microscope (SEM, Philips XL 30 SFEG). Phase composition, microstructure, and elemental distribution analyses of the deposit layer were performed using an X-ray diffractometer (Rigaku DMAX 2200) and an embedded EDX digital controller (EDX detector operating $15 \mathrm{kV}$ ) attached to the SEM. X-ray diffraction pattern measurements were performed in the range of $20^{\circ}$ to $90^{\circ}$, at a scanning speed of $2^{\circ} \mathrm{min}^{-1}$, in $\mathrm{Cu} \mathrm{K}{ }_{\alpha}$ radiation, and with the value of $\lambda$ of $0.1541 \mathrm{~nm}$.

\section{Results and discussions}

The ESD coating process has been successfully applied to deposit CrC-NiCr, TiCN, WC-Co and TiWC-Co electrode materials onto the steel substrates. The roughness of surfaces and thickness of each type of coating is presented in Fig. 1. The average roughness of all coatings was ranging from $3.32 \mu \mathrm{m}$ to $4.95 \mu \mathrm{m}$. The minimal roughness value was achieved on TiCN electrode material (Fig. 1a). The average thicknesses of coatings with pulse amplitude of current of 200 A were about 40.03, $22.35,23.05$ and $19.75 \mu \mathrm{m}$, respectively. The thicknesses of $\mathrm{CrC}-\mathrm{NiCr}$ coating were greater, approximately $17-$ $24 \mu \mathrm{m}$, than those obtained with other electrode materials (Fig. 1b). According to these results, as the amplitude of pulse current raises the thicknesses of coatings and roughness of surfaces increase. It can be said that the amount of the mass transfer depends on the energy of pulses and also some other properties (such as composition, thermal and electrical conductivity).

A typical SEM micrograph for a cross-section of the coatings and also the distribution of elements in the coatings on the steel substrates is shown in Fig. 2. These data were obtained by EDX elemental line scanning technique. According to the elemental graphs, the amount of elements of electrode materials such as $\mathrm{Cr}, \mathrm{Ni}$ and $\mathrm{C}$ in the CrC-NiCr coating (Fig. 2a), $\mathrm{Ti}$ and $\mathrm{Ni}$ in the $\mathrm{TiCN}-\mathrm{Ni}$ coating (Fig. 2b), W in the WC-Co coating (Fig. 2c), $\mathrm{Ti}$ and $\mathrm{W}$ in the TiWC-Co coating (Fig. 2d) increase from the interfaces of coatings and substrate towards the surface of the coatings, while amount of Fe decreases. Thus, it can be said that these results were reasonable and usual.

The XRD patterns of coated samples and steel substrate are shown in Fig. 3. According to XRD analysis of the coated samples and the substrate, the XRD patterns of $\mathrm{CrC}-\mathrm{NiCr}$, TiCN, WC-Co and TiWC-Co coatings mainly consist of $\alpha-\mathrm{Fe}, \mathrm{Cr}_{7} \mathrm{C}_{3}, \mathrm{NiC}, \mathrm{TiC}_{0.7} \mathrm{~N}_{0.3}$, $\mathrm{Fe}_{3} \mathrm{~W}_{3} \mathrm{C}$ and $\mathrm{WC}$, respectively. It is clear that the $\alpha-\mathrm{Fe}$ phase belongs to steel substrate and the other phases are
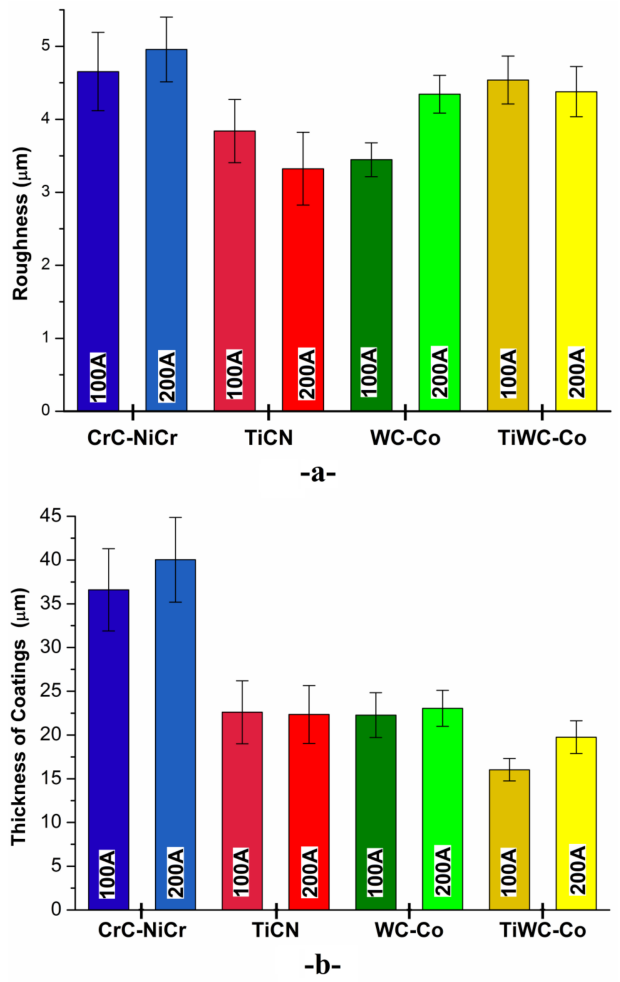

Fig. 1. (a) The roughness of surface and (b) the thickness of coatings for different hard alloy electrode materials, obtained at amplitudes of current of 100-200 A.
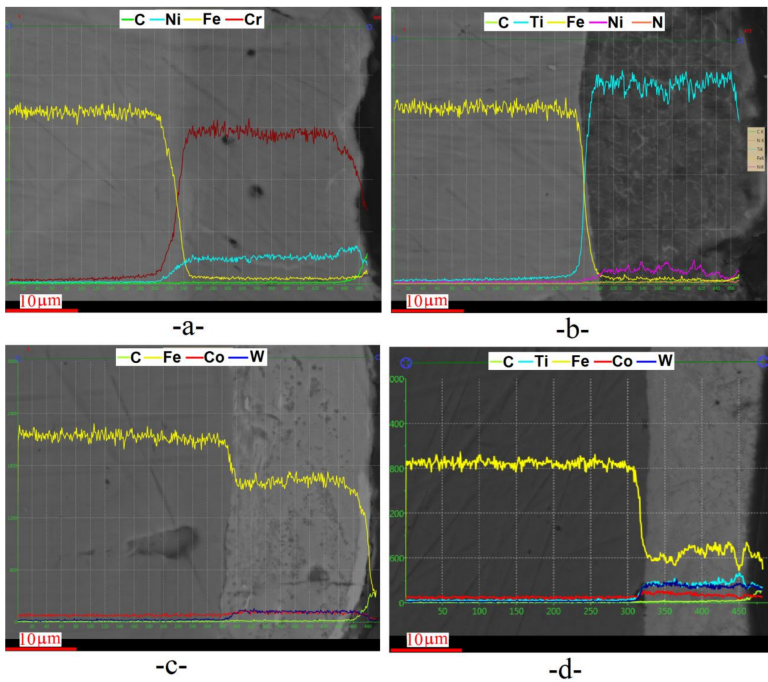

Fig. 2. SEM micrographs and graphical representations of elemental distribution along the cross-section of a) $\mathrm{CrC}-\mathrm{NiCr}$, b) TiCN-Ni, c) WC-Co and d) TiWCCo coatings.

the result of ESD coating process. They are related to the alloying of the coating and the steel substrate and their rapid solidification.

The microhardness distributions along the depth of coatings on the steel substrate are presented Fig. 4 . It is clear that there is a significant increase in the hard- 


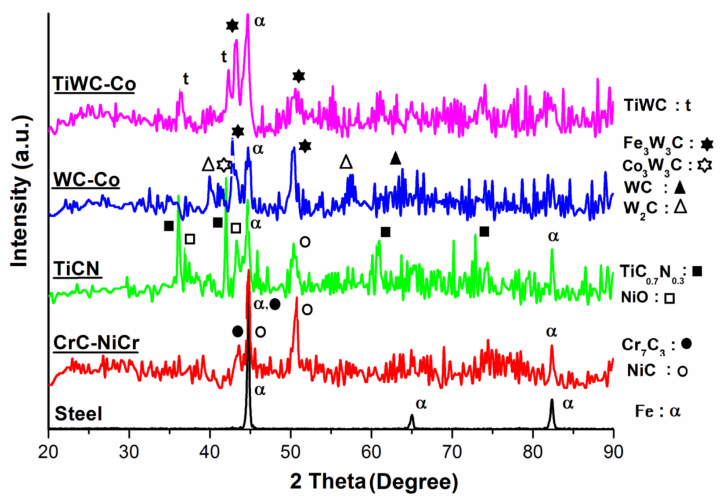

Fig. 3. The XRD patterns of the coated samples and the steel substrate.

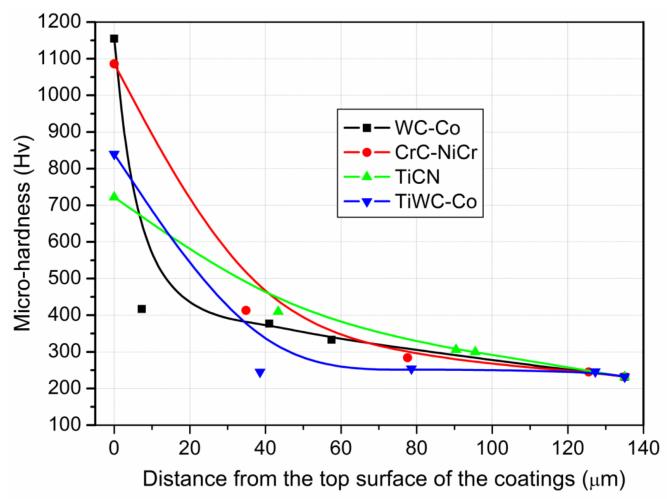

Fig. 4. Microhardness depth profiles of all coatings on steel substrate.

ness values as a result of coating after each of the coating processes. The hardness of the $\mathrm{WC}-\mathrm{Co}, \mathrm{CrC}-\mathrm{NiCr}$, TiCN and TiWC-Co coated layers are 1155, 1086, 840 and $720 \mathrm{HV}$, respectively, whereas the hardness of the substrate is $232 \mathrm{HV}$. The hardness value depends on various parameters, such as phase composition and microstructure. These average microhardness values of the ESD coatings are 3.1-5 times greater than that of the uncoated St 35 steel, since these coatings mainly consist of phases with high hardness, such as $\mathrm{WC}, \mathrm{Cr}_{7} \mathrm{C}_{3}$ and $\mathrm{TiC}_{0.7} \mathrm{~N}_{0.3}$ (Fig. 4).
The dependence of frictional and normal forces on the distance in the scratch tests for all coatings is presented in Fig. 5. High and comparable change of the critical load values can be connected with the failure of coatings. The initial cracking, extensive cracking and delamination of the coating from the steel surface are represented by Lc1, Lc2 and Lc3, respectively. Results of the experimental scratch test are given in Table. The critical load values of the WC-Co (Fig. 5c) and TiWC-Co (Fig. 5d) coatings are greater than those of other coatings $(\mathrm{CrC}-\mathrm{NiCr}$ in Fig. 5a, TiCN-Ni in Fig. 5b), because these coatings exhibit a very good adhesion to the substrate. It can be concluded that these critical load values depend on phase structure and microstructure of the coatings. Both WC-Co and TiWC-Co coatings mainly consist of $\mathrm{Fe}_{3} \mathrm{~W}_{3} \mathrm{C}$ and WC
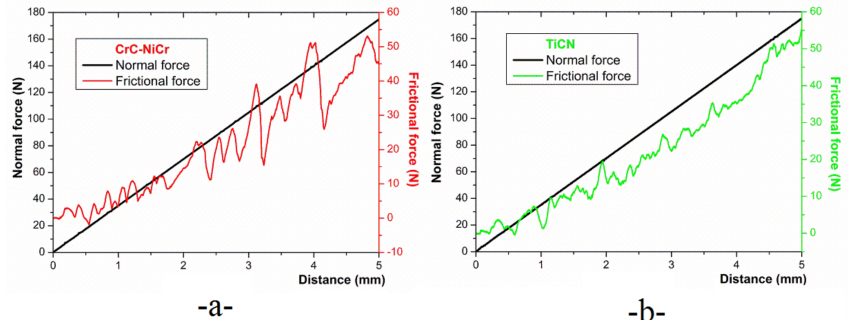

$-b-$

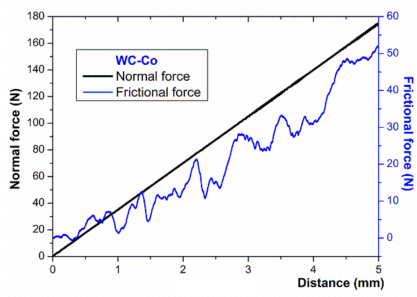

$-c-$

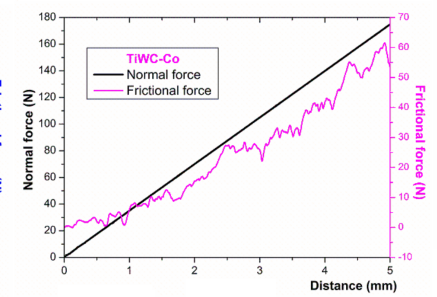

$-d-$
Fig. 5. The normal and frictional forces as function of distance in scratch tests of all coatings.

phases. The WC has been well known for its exceptional hardness. The presence of $\mathrm{Fe}_{3} \mathrm{~W}_{3} \mathrm{C}$ phase is related to the alloying of the coating and the steel substrate and their solidification. So it can be said that the coating is well metallurgically bonded with steel substrate due to the presence of $\mathrm{Fe}_{3} \mathrm{~W}_{3} \mathrm{C}$ phase.

Experimental results of scratch test obtained for the ESD coatings.

TABLE

$F_{n}$ - Normal force, $F_{f}$ - Frictional force, $d$ - distance.

\begin{tabular}{c|c|c|c|c|c|c|c|c|c}
\hline \hline \multirow{2}{*}{ Sample } & \multicolumn{3}{|c|}{ Lc1 } & \multicolumn{3}{c|}{ Lc2 } & \multicolumn{3}{c}{ Lc3 } \\
\cline { 2 - 12 } & $F_{n},[\mathrm{~N}]$ & $F_{f},[\mathrm{~N}]$ & $d,[\mathrm{~mm}]$ & $F_{n},[\mathrm{~N}]$ & $F_{f},[\mathrm{~N}]$ & $d,[\mathrm{~mm}]$ & $F_{n},[\mathrm{~N}]$ & $F_{f},[\mathrm{~N}]$ & $d,[\mathrm{~mm}]$ \\
\hline $\mathrm{CrC}-\mathrm{NiCr}$ & 19.572 & 1.712 & 0.553 & 113.026 & 15.513 & 3.234 & 160.445 & 42.299 & 4.588 \\
\hline TiCN & 20.790 & 0.089 & 0.591 & 61.791 & 9.273 & 1.761 & 130.539 & 31.772 & 3.724 \\
\hline WC-Co & 51.134 & 4.527 & 1.460 & 116.686 & 24.006 & 3.332 & 169.219 & 48.354 & 4.840 \\
\hline TiWC-Co & 32.241 & 0.863 & 0.921 & 125.688 & 32.224 & 3.594 & 159.826 & 49.895 & 4.568
\end{tabular}

\section{Conclusions}

In this study, the electrospark deposition (ESD) process has been successfully applied to deposition of hard WC-Co, CrC-NiCr, TiCN and TiWC-Co layers onto St
37 steel substrates in air. By using ESD process, we have been able to obtain very hard coatings, showing a good metallurgical bond with the steel substrates.

The WC-Co coating exhibits a higher microhardness and the best adhesion to the steel substrate among all 
tested coatings, due to the presence of $\mathrm{WC}$ and $\mathrm{Fe}_{3} \mathrm{~W}_{3} \mathrm{C}$ phases.

The $\mathrm{CrC}-\mathrm{NiCr}$ coating shows thicker coating feature than those obtained with other electrode materials. It can be said that it has the best mass transfer mechanism in the ESD coating processes, due to the presence of $\mathrm{CrC}$ and $\mathrm{NiC}$ phases which have good thermal and electrical conductivity in this coating.

\section{Acknowledgments}

The authors would like to thank Mr. Adem Şen for running the X-ray diffractometer, Mr. Ahmet Nazım for using Scanning Electron Microscopy at Gebze Technical University.

\section{References}

[1] K. Korkmaz, H.İ. Bakan, Kovove Mater. 48, 153 (2010).

[2] P.Z. Wang, G.S. Pan, Y. Zhou, J.-X. Qu, H.-S. Shao J. Mater. Eng. Perform. 6, 780 (1997).

[3] M.H. Staia, A. Fragiel, et al., Wear 251, 1051 (2001).

[4] A. Agarwal, N.B. Dahotre, Surf. Coat. Technol. 106, 242 (1998).

[5] R.N. Johnson, G.L. Sheldon, J. Vac. Sci. Technol. A 4, 2740 (1986).

[6] A. Lesnjak, J. Tusek, Sci. Technol. Weld. Joining 7, 391 (2002).

[7] M.S. Yılmaz, E. Atar, O. Şahin, E.S. Kayalı, Acta Physica Polonica A 125, 593 (2014).

[8] K. Korkmaz, A.V. Ribalko, Kovove Mater. 49, 265 (2011).

[9] A.V. Ribalko, K. Korkmaz, O. Sahin, Surf. Coat. Technol. 202, 3591 (2008). 